D.O.I: $10.3895 / \mathrm{S} 1808-04482013000100007$

\title{
UTILIZAÇÃO DE AÇÕES DE MARKETING VERDE NOS PRODUTOS QUE COMPÕEM A CESTA BÁSICA BRASILEIRA
}

\section{USE OF SHARES IN GREEN MARKETING PRODUCT THAT COMPOSE A BRAZILIAN STAPLE FOOD}

\author{
Jessiany Fernandes Braga ${ }^{1}$; José Aparecido da silva ${ }^{2}$; Lucyanno Moreira Cardoso de Holanda ${ }^{3}$ \\ ${ }^{1}$ Faculdade Vale do Ipojuca FAVIP/DEVRY \\ jhessyanny_kiss@hotmail.com \\ ${ }^{2}$ Faculdade Vale do Ipojuca FAVIP/DEVRY \\ cidos_caramelos@hotmail.com \\ ${ }^{3}$ Faculdade Vale do Ipojuca FAVIP/DEVRY \\ lholanda@favip.edu.br
}

\begin{abstract}
Resumo
A preocupação com o meio ambiente vem aumentando nas últimas décadas, esse fato acontece devido a diversos fatores, tais como a necessidade de sobrevivência do homem e a sua percepção da limitação dos recursos naturais. Diante desse cenário, uma das ferramentas que pode ser utilizadas pelas empresas para permitir conciliar lucratividade e responsabilidade social vem ser o chamado marketing verde ou ecológico, onde o mesmo leva informações sobre produto e produtor, além de contribuir para adequação das empresas junto aos órgãos responsáveis pela legislação ambiental, e em relação aos concorrentes servindo como uma variável competitiva. Deste modo o estudo buscou identificar as ações de marketing verde encontradas nos produtos que compõem a cesta básica, em duas grandes redes supermercadistas localizadas em Caruaru-PE. Através da pesquisa de campo foi possível identificar oito produtos que continham ações de marketing verde esses foram: Feijão, Arroz, Farinha, Pão Francês ou de Forma, Café em Pó, Açúcar, Óleo ou banha e Manteiga. Diante do explicitado, é possível inferir que as empresas estão preocupadas com as ações de marketing verde e começam a usar em produtos básicos como os que compõem a cesta básica brasileira.
\end{abstract}

Palavras-chave: marketing verde; cesta básica; produtos verdes.

\section{Introdução}

A preocupação com o meio ambiente vem aumentando nas últimas décadas, esse fato acontece devido a diversos fatores, tais como a necessidade de sobrevivência do homem e a sua percepção da limitação dos recursos naturais.

Partindo dessa premissa, o homem vem se conscientizando de seu papel social, e exigindo mesmo que indiretamente, que as organizações adquiram comportamentos 
responsáveis visando os impactos ambientais negativos provenientes de suas atividades produtivas e mercadológicas (TEIXEIRA, 2009).

Quanto mais cedo as organizações enxergarem essa questão ambiental como um investimento e um diferencial competitivo, maior será a sua probabilidade de sobreviver e lucrar. Assim esta preocupação com o meio ambiente vem levando a uma modificação no perfil do consumidor e no padrão de escolha de um produto ou serviço no mercado (CHURCHILL \& PETER, 2000).

Diante da mudança de cenário, uma das ferramentas que pode ser utilizadas pela empresa para permitir conciliar lucratividade e responsabilidade social vem ser o chamado marketing verde ou ecológico, onde o mesmo leva informações sobre produto e produtor, além de contribuir para adequação das empresas junto aos órgãos responsáveis pela legislação ambiental, e em relação aos concorrentes servindo como uma variável competitiva.

Dessa maneira, as empresas devem se adaptar às necessidades de seus clientes, atualizando suas estratégias de marketing, visto que essas devem ir além da publicidade e divulgação dos produtos e serviços (BAROTO, 2007).

Ante ao contexto inicial, o objetivo do artigo é identificar as ações de marketing verde encontradas nos produtos que compõem a cesta básica brasileira, em duas redes supermercadistas localizadas em Caruaru-PE.

Segundo a pesquisa do Departamento Intersindical de Estatística e Estudos Socioeconômicos - DIEESE, de 06/2012 a cesta básica nacional, ou ração essencial mínima, é composta por treze (13) gêneros alimentícios, são eles Carne, Leite, Feijão, Arroz, Farinha, Batata, Tomate, Pão Francês ou de Forma, Café em Pó, Açúcar, Óleo ou banha, Manteiga, Frutas/Banana.

O critério para seleção dos produtos foi que os mesmos devem conter ações de marketing verde na embalagem, banner, panfletos ou através de informações de funcionários.

Além deste tópico introdutório, o artigo é composto por quatro partes. No referencial teórico aborda os principais conceitos de marketing, marketing verde, consumidor verde e produtos verdes. Em seguida, são explicitados os procedimentos metodológicos, depois a apresentação e análise dos resultados obtidos, seguida pelas considerações finais.

\section{Fundamentação teórica}

\subsection{Marketing}

A palavra marketing provém da junção de duas palavras inglesas: "Market" e "ing", mercado e ação/movimento, então é possível definir marketing como o mercado em 
movimento, existem também quem entenda o marketing como mercado de comercialização (KOTLER, 1998).

Dias (2007, p.40) relata que o marketing surgiu no início do século XX, com o intuito de solucionar problemas com a distribuição e venda de produtos, o mesmo era muitas vezes mal utilizado e mal interpretado, tornando-se alvo de críticas por induzir ao consumo exagerado, provocando aumento da extração dos recursos naturais e geração de resíduos de todo tipo.

Com o objetivo de esclarecer o conceito de marketing, o Quadro 1 apresenta alguns estudiosos sobre o tema.

Quadro 1 - conceitos sobre marketing

\begin{tabular}{|c|c|}
\hline Autor & Conceito \\
\hline Peter Drucker (1954). & "Uma força poderosa a ser considerada pelos administradores". \\
\hline $\begin{array}{l}\text { Ohio State University } \\
(1965) .\end{array}$ & $\begin{array}{l}\text { "O Processo na sociedade pelo qual a estrutura da demanda para bens } \\
\text { econômicos e serviço é antecipado ou abrangido e satisfeita através } \\
\text { da concepção, promoção, troca e distribuição física de bens e } \\
\text { serviços". }\end{array}$ \\
\hline $\begin{array}{l}\text { American Marketing } \\
\text { Association }- \text { AMA } \\
\text { (apud Kotler, Kartajaya } \\
\text { e Setiawan, 2010, p. 18). }\end{array}$ & $\begin{array}{l}\text { "Marketing é a atividade, conjunto de instituições e processos para } \\
\text { criar, comunicar, oferecer e trocar ofertas que tenham valor para } \\
\text { consumidores, clientes, parceiros e para a sociedade como um todo". }\end{array}$ \\
\hline Las Casas (2006, p.10). & $\begin{array}{l}\text { "Engloba todas as atividades concernentes às relações de troca, } \\
\text { orientadas para a satisfação dos desejos e necessidades dos } \\
\text { consumidores visando alcançar determinados objetivos de empresas } \\
\text { ou indivíduos e considerando sempre o ambiente de atuação e o } \\
\text { impacto que essas relações causam no bem estar da sociedade". }\end{array}$ \\
\hline Kotler (2000). & $\begin{array}{l}\text { "Marketing é o processo por meio dos quais pessoas e grupos de } \\
\text { pessoas obtêm aquilo de que necessitam e que desejam com a criação, } \\
\text { oferta e livre negociação de produtos e serviços de valor com outros". }\end{array}$ \\
\hline $\begin{array}{l}\text { Kotler e Armstrong } \\
(2003, \text { p.3). }\end{array}$ & $\begin{array}{l}\text { "Marketing como um processo administrativo e social pelo qual } \\
\text { indivíduos e grupos obtêm o que necessitam e desejam, por meio da } \\
\text { criação, oferta e troca de produtos e valor com os outros." }\end{array}$ \\
\hline
\end{tabular}

Analisando as definições acima citadas, percebe-se que não há um consenso entre os autores sobre o conceito de marketing, porém é comum observar convergência de algumas palavras tais como: necessidade, desejo, valores, trocas, mercados, produtos, custos e satisfação, dentre outras.

Desta forma é possível compreender que o marketing envolve a criação de valor, a identificação e a satisfação das necessidades humanas e sociais, com um efeito lucrativo para ambas as partes. Portanto por trás dessa visão, estaria, de um lado a influencia da demanda ao oferecer produtos apropriados, atraentes, adquirível e facilmente disponíveis aos consumidores, e pelo outro a estratégia da empresa em lucrar suprindo as necessidades e desejos de seus consumidores. 
Ampliando este pensamento, onde o marketing é compreendido como uma relação de troca, com a finalidade de satisfazer ambas as partes que nela intervêm, tanto a empresa como a sociedade, onde os consumidores têm papel fundamental na criação de novos produtos e serviços, adequados às reais necessidades do mercado.

O próximo tópico abordará o tema foco da pesquisa, o marketing verde e suas peculiaridades.

\subsection{Marketings verdes}

A partir da necessidade das empresas de se adequarem ao novo tipo de consumidor, os chamados "verdes", surgiu o marketing verde ou ecológico (DIAS, 2009). Ferramenta esta que não se limita apenas a divulgar seus produtos, mais também se estende como estratégia de utilização de meio ambiente como variável competitiva, além de auxiliar na resolução dos problemas derivado da relação homem meio ambiente.

Diante disso, várias definições foram encontradas para conceituar o que é marketing verde ou ecológico uma das mais objetivas delas relata que "é um processo de gestão integrada, responsável pela identificação, antecipação e satisfação das demandas os clientes e da sociedade, de uma forma rentável e sustentável" (PEATIIE, 1995).

No marketing ecológico o cliente não é o único público alvo ser atingido, mesmo ele sendo o mais importante, existe outros públicos que devem ser considerados por se envolverem diretamente ou indiretamente com a empresa. Pois estes podem representar obstáculos na sobrevivência da organização, são eles, os grupos ambientalistas, os fornecedores, os distribuidores, a comunidade mais próxima da unidade de produção e o governo (DIAS, 2009).

Neste sentido, deve-se ter sempre um equilíbrio entre as necessidades dos seus clientes e aqueles da sociedade mais geral, que nem sempre são as mesmas [...]. Um produto pode interessar muito a determinado segmento da sociedade, mas, se sua produção envolve a contaminação do local onde se situa a unidade produtiva, neste momento há que se ter uma preocupação prioritária em relação à sociedade mais geral (DIAS, 2009. p. 140).

A partir deste contexto, toda empresa é responsável pelo produto ou serviço, caso as mesmas, com suas atividades produtivas prejudiquem ao meio ambiente, tem por obrigação encontrar meios e maneiras para solucionar o problema, podendo reduzir ou até mesmo a eliminar estes danos.

Em tal conformação as organizações estão revendo suas atividades e processos produtivos, e se adaptando a esta nova realidade.

As empresas que se comprometerem a implantar as ferramentas de marketing verde poderão obter significativos benefícios, tais como, estratégias de comunicação, créditos por 
trabalhar sustentavelmente, vantagem comparativa em relação às marcas concorrentes (selo verde) e etc.

\begin{abstract}
Não é suficiente falar a linguagem verde; as companhias devem ser verdes, longe da questão de apenas fazer publicidade que muitos comerciantes perceberam originalmente, abordagem satisfatória de preocupação ambiental requer um esverdeamento completo que vai fundo na cultura coorporativa. Somente por intermédio de políticas ambientais fortes e profundamente valorizadas é que a maioria dos produtos e serviços saudáveis podem ser desenvolvidos. É só por meio da criação de uma ética ambiental que abranja toda a empresa que estratégias de marketing podem ser executadas (OTTMAN, 1994. p. 56.).
\end{abstract}

A publicidade "verde", em alguns produtos é alardeada como ecológicos, por terem origem em plantações orgânicas, ou estarem livres de substancias agressivas, ou por não agredirem o meio natural, ou por motivos semelhantes. [...] a profusão e a quantidades de alegações que afirmam que o produto é ecológico têm confundido o consumidor, que passa a ver com desconfiança essa divulgação, pois não sabe se as empresas realmente cumprem com as afirmações da propaganda (DIAS, 2009. p. 150/151).

Em tal conformação, é difícil saber se as informações declaradas são realmente verdadeiras, se a idoneidade da certificação declarada nas informações é realmente legítima, daí parte dos consumidores e órgãos responsáveis serem bastante rigorosos e cautelosos ao analisarem e comprarem estes produtos ou adquirirem estes serviços.

Portanto, estas empresas ambientalmente responsáveis estão inseridas em uma nova realidade, onde o consumidor encontra preocupado com os recursos naturais, que por sua vez, transformam o poder de compra em instrumento para impulsionar as organizações a também abraçarem a sustentabilidade, formando uma aliança em prol do meio ambiente. Deste modo as empresas vêm se deparando, com este novo perfil de consumidor, os ecológicos, ou verdes, que serão explanados neste tópico decorrente.

\title{
2.3 Consumidores Verdes
}

O consumidor verde é aquele indivíduo cujo comportamento de compra é influenciado pelas suas preocupações ambientais (DIAS, 2009).

O mesmo autor menciona que

Deste modo, se acirra o desnivelamento entre fornecedor e consumidores, onde este novo perfil de consumidor e cidadãos "verdes" não são apenas uma simples tendência. Estes sem duvidas são o presente e o futuro das sociedades civilizadas, conscientes e com preocupação com as gerações futuras. É como se fosse um ciclo composto por: problema, efeito, solução e resultado (DIAS, 2009).

Para entender sobre esse comportamento do cliente em relação a produtos que sejam responsavelmente sustentável, Ottman (2012) menciona que foi realizada uma pesquisa com a 
população dos Estados Unidos da América (EUA), apresentada pelo Natural Marketing Institute (NMI) nomeada de The LOHAS Report: Consumers and Sustainability sobre a divisão do consumidor verde, que pode ser classificada em cinco tons de verde, ou seja, cada consumidor é considerado por um tom de verde. No Quadro 2, a seguir, é possível verificar como esse segmentação é realizado.

Quadro 2 - Segmentação do consumidor verde

\begin{tabular}{|c|l|}
\hline SEGMENTO & \multicolumn{1}{|c|}{ CARACTERÍSTICAS } \\
\hline \multirow{2}{*}{ Lohas } & $\begin{array}{l}\text { Lifestyles of Health and Sustainability (LOHAS), representa os consumidores mais } \\
\text { conscientes a respeito do meio ambiente, holisticamente orientados e ativos. } \\
\text { Costumam ter o dobro de probabilidade de associar seus valores pessoais a } \\
\text { empresas e suas marcas. Procuram sempre informações para garantir que os } \\
\text { produtos que compram estejam sincronizados com seus padrões ambientais e } \\
\text { sociais. }\end{array}$ \\
\hline Naturalites & $\begin{array}{l}\text { Esse segmento procura adotar um estilo de vida saudável e acreditam em filosofias } \\
\text { que ligam mente-corpo-espírito. São motivados por palavras como } \\
\text { "antibactericida", "sem produtos sintéticos" e "naturais". Preocupam-se com os } \\
\text { efeitos prejudiciais dos produtos químicos em artigos como tinta, cosméticos e } \\
\text { alimentos. }\end{array}$ \\
\hline Drifters & $\begin{array}{l}\text { São motivados por tendências mais do que por fortes ideais. São movidos pela } \\
\text { "moda" do verde. Adquirem produtos verdes para serem vistos pela sociedade. }\end{array}$ \\
\hline Conventionals & $\begin{array}{l}\text { São bons em reciclar e reusam as coisas num esforço de reduzir o lixo e economizar } \\
\text { centavos. Eles tem consciência das questões ambientais, mas não estão tão } \\
\text { motivados a comprar alimentos orgânicos ou outros produtos saudáveis como os } \\
\text { LOHAS pela saúde e pelo meio ambiente. }\end{array}$ \\
\hline Unconcerned & $\begin{array}{l}\text { São os chamados "despreocupados". Demonstram a menor noção de } \\
\text { responsabilidade de todos os segmentos. }\end{array}$ \\
\hline
\end{tabular}

Fonte: Adaptado de Ottman (2012)

Ainda segundo a autora, diante dessas características, é possível também classificar o comportamento do consumidor verde em subsegmentos, caracterizados por questões e causas específicas como: poupadores de recursos, fanáticos por saúde, amantes dos animais e entusiastas da natureza. O Quadro 3 apresentará cada subsegmento distintamente.

Quadro 3 - Segmentação por interesse verde

\begin{tabular}{|c|l|}
\hline SUBSEGMENTO VERDE & \multicolumn{1}{|c|}{ CARACTERÍSTICAS } \\
\hline Poupadores de recursos & $\begin{array}{l}\text { Esse subsegmento detesta lixo. São sempre vistos com produtos } \\
\text { reutilizáveis, recusam produtos com excesso de embalagem, trocam } \\
\text { continuamente produtos que desperdice água e energia. }\end{array}$ \\
\hline Fanáticos por saúde & $\begin{array}{l}\text { São indivíduos que se preocupam com o câncer causado pelo sol, que } \\
\text { temem os impactos, dos inseticidas na saúde de seus filhos. Usam } \\
\text { protetor solar, pagam mais por alimentos orgânicos, produtos e limpeza } \\
\text { não tóxica e produtos naturais de cuidados de animais. }\end{array}$ \\
\hline Amantes dos animais & $\begin{array}{l}\text { Ama todos os animais (adotados ou abandonados). São vegetarianos ou } \\
\text { veganos, se comprometem com um estilo de vida em defesa dos } \\
\text { animais. }\end{array}$ \\
\hline Entusiastas da natureza & $\begin{array}{l}\text { Adotam o ar livre e passam grande parte de seu tempo envolvidos em } \\
\text { atividades como acampamento, escalada, esquiar, caminhar. Levam a } \\
\text { sério a redução do impacto ambiental de suas atividades recreacionais. }\end{array}$ \\
\hline
\end{tabular}

Fonte: Adaptado de Ottman (2012) 
Deste modo, através desta consciência verde, iniciada por alguns consumidores que se preocupam com o processo pelo qual passa os produtos até chegarem a suas residências, processo esse que consiste em economizar energia, matéria-prima e serem produzidos de maneira menos nociva à natureza, gerando os produtos chamados verdes. O próximo tópico aborda mais detalhadamente esses produtos.

\title{
2.4 Produtos Verdes
}

Sem dúvida que os produtos verdes são fundamentais para o marketing, produtos estes que são fabricados e encaminhados ao mercado para satisfazer os desejos e necessidades de seus clientes.

Kotler (1998) caracteriza que "Os produtos verdes são algo que pode ser oferecidos a um mercado para sua apreciação, aquisição, uso ou consumo para satisfazer a um desejo ou necessidade". Hans Johr (1994) complementa que o produto verde é aquele que cumpre com as mesmas funções dos produtos equivalentes e causa um dano ambiental inferior, durante todo seu ciclo.

Porém Ottman (2012, p. 94) alerta que, "não existe um produto verdadeiramente "verde", porque todos os produtos, por mais que sejam bem elaborados, usam recursos e geram lixo. Assim, o "verde" é um termo relativo, e alguns produtos são mais verdes por determinados motivos ou em certas circunstâncias".

Dias (2009, p. 119) complementa que,

\begin{abstract}
um produto verde (ou ecológico) é, portanto, aquele que cumpre as mesmas funções dos produtos equivalentes e causa um dano ao meio ambiente inferior, durante todo o seu ciclo de vida. E, quanto ao produto em si, deve ser analisada sua composição, se é reciclável, se agride ou não o meio ambiente e, quanto à embalagem, se o material também pode ser reciclado. É importante levar em consideração que o dano ao meio ambiente é um cálculo complexo e em muitas fases subjetivo, pelo que é necessário realizar constantemente a avaliação dos produtos ecológicos e não ecológicos mediante uma análise do seu ciclo de vida (DIAS, 2009, p. 119).
\end{abstract}

Portanto, pode-se dizer que a população esta se declarando motivada a comprar produtos que sejam fabricados de maneira ecológica, bem como, as empresas estão mais impulsionadas a oferecer este tipo de produto ao mercado, e demonstram isso nos produtos através de certificações, como o selo verde, e de outras informações sobre o produto contidas na embalagem do mesmo.

\section{Aspectos metodológicos}

O capítulo apresenta o método de abordagem, classificação da pesquisa, população e amostra, coleta dos dados e o tratamento das informações. 


\subsection{Método científico}

O método utilizado foi o indutivo. Os resultados obtidos dos produtos que compõem a cesta básica podem ser generalizados para outros tipos de produtos presente nos supermercados pesquisados.

\subsection{Classificação da pesquisa}

A pesquisa pode ser classificada como aplicada, qualitativa, descritiva e estudo de caso.

\subsubsection{Quanto à natureza}

A pesquisa aplicada. Os conhecimentos derivados do estudo podem contribuir para as organizações na formulação ou reformulação de ações de marketing verde para a divulgação dos produtos.

\subsubsection{Quanto à forma de abordagem do problema}

Pesquisa qualitativa. O uso da abordagem qualitativa nessa pesquisa permitiu identificar e analisar ações de marketing verde utilizadas nos produtos que compõem a cesta básica brasileira.

\subsubsection{Quanto aos objetivos}

É classificada como pesquisa exploratória. Permite identificar as ações de marketing verde usada para a divulgação dos produtos no mercado para chamar atenção dos consumidores.

\subsubsection{Quanto aos procedimentos técnicos}

Estudo de caso. Como se deseja estudar profundamente a relação entre o uso de ações de marketing verde em produtos que compõem a cesta básica em duas redes de supermercados em Caruaru-PE e observar como essa divulgação nos produtos chama atenção aos consumidores, considerou o estudo de caso o mais indicado.

\subsection{População e amostra}

A população, conforme o DIEESE, é composta por 13 (treze) gêneros alimentícios, são eles Carne, Leite, Feijão, Arroz, Farinha, Batata, Tomate, Pão Francês ou de Forma, Café em Pó, Açúcar, Óleo ou banha, Manteiga, Frutas/Banana. Já a amostra desse estudo é igual à população. 


\subsection{Instrumento de coleta de dados e tratamento das informações}

Para esta pesquisa, considerando que se trata de um estudo de caso, e desejando saber as ações de marketing verde encontradas nos produtos que compõem a cesta básica brasileira, em duas redes supermercadistas, foi utilizada como instrumento de coleta de informações a observação sistemática em equipe.

Os produtos que compõem a cesta básica foram identificados nos supermercados pesquisados e separados. Após a separação, utilizou o critério inicial, que esses produtos tivessem ações de marketing verde na embalagem, banner, panfletos ou através de informações de funcionários. Os produtos, bem como as ações foram identificados e fotografados e transformadas em figuras (item 4.3). Os dados tabulados podem ser visualizadas no Quadro 4.

\section{Resultados}

Esta seção apresentara os resultados provenientes da pesquisa realizada em duas grandes redes supermercadistas da cidade de Caruaru-PE, com a finalidade de preservar a identidade das mesmas, essas foram denominadas de rede supermercadista " $A$ " e "B".

Quadro 4 - Marcas pesquisadas e suas ações de marketing verde

\begin{tabular}{|c|c|c|c|c|}
\hline Produtos & $\begin{array}{c}\text { Quantidade de } \\
\text { marcas pesquisadas } \\
\text { no supermercado } \\
\text { "A" }\end{array}$ & $\begin{array}{c}\text { Quantidade de } \\
\text { marcas pesquisadas } \\
\text { no supermercado } \\
\text { "B" }\end{array}$ & $\begin{array}{c}\text { Ações verdes do } \\
\text { supermercado A }\end{array}$ & $\begin{array}{c}\text { Ações verdes do } \\
\text { supermercado B }\end{array}$ \\
\hline Leite & 3 & 3 & SIM & SIM \\
\hline Margarina & 3 & 3 & SIM & SIM \\
\hline Feijão & 3 & 2 & SIM & SIM \\
\hline Arroz & 3 & 2 & SIM & SIM \\
\hline Farinha & 3 & 3 & SIM & SIM \\
\hline Pão de forma & 2 & 1 & SIM & SIM \\
\hline Café & 3 & 3 & SIM & SIM \\
\hline Açúcar & 3 & 3 & SIM & SIM \\
\hline Óleo & 3 & 1 & NÃO & NÃO \\
\hline Batata & 1 & 2 & IDENTIFICADO & IDENTIFICADO \\
\hline Tomate & 1 & 2 & NÃO & NÃO \\
\hline Banana & 1 & 5 & IDENTIFICADO & IDENTIFICADO \\
\hline Carne & 5 & IDENTIFICADO & IDENTIFICADO \\
\hline
\end{tabular}

Fonte: Pesquisa de Campo

Como é possível observar nove produtos apresentam algum tipo de ação verde e em quatro produtos não foi identificada nenhuma ação. O próximo tópico apresenta mais detalhadamente os resultados da rede supermercadista " $\mathrm{A}$ ". 


\subsection{Rede supermercadista " $A$ "}

Primeiramente foi visitada a rede supermercadista "A", onde foram analisadas as ações verdes existentes nos produtos pesquisados. Iniciando pelo item leite, foram observadas três marcas diferentes, onde todas possuíam algum tipo de ação verde. A primeira foi à presença do selo da FSC - Forest Stewardship Council (Conselho de Manejo Florestal), selo este que significa que o papel utilizado na embalagem foi certificado e é proveniente de florestas manejadas de forma responsável, além de lembretes para se reciclar a embalagem após seu descarte.

No caso do item feijão foram identificadas três marcas diferentes e o mesmo fato aconteceu com o item anterior, de também possuírem ações verdes, diferindo apenas nas simbologias, e acrescentando ainda o fator informativo, manter a cidade limpa e que o plástico usado em sua embalagem deve ser reciclável.

Para o item arroz, também foram analisadas três marcas distintas, estas apresentam as seguintes ações, que o plástico é reciclável, e em duas das marcas a simbologia era igual relatando o número quatro (4) PEBD (polietileno de baixa densidade) em seu interior, que significa que é o segundo material mais usado em rótulos plásticos de comidas e que pode ser reciclado.

Partindo para o item farinha, três marcas analisadas, constando em todas elas ações verdes, essas foram identificadas em frases, preservar a natureza, recicle as embalagens, e manter a cidade limpa.

Já para no item pão, foram analisadas duas marcas, onde foram constatadas ações verdes de seus fabricantes, sua simbologia indicou que em um deles o material de sua embalagem é polietileno de baixa densidade muito comumente utilizado e pode ser reciclado, já a outra marca utiliza apenas o polipropileno que também é aceito para reciclagem.

Em se tratando do café em pó, a pesquisa ocorreu em três marcas, suas simbologias diferiram, uma delas relata que a empresa fabricante possui o selo de parceira da natureza do IBDN (Instituto Brasileiro de Defesa da Natureza), a outra que sua embalagem contém o selo da FSC, e apresenta impressa a frase qualidade de vida é respeito ao meio ambiente.

Já o item açúcar também em sua simbologia demonstrou ações verdes, e foram analisadas três marcas conhecidas popularmente, em uma delas diz que em seu produto são utilizadas embalagens recicláveis, além de pedir para manter a cidade limpa.

Agora relatando as ações verdes existentes nas três marcas observadas de óleo, em uma delas diz que sua tampa foi reduzida, que seu rotulo é utilizado o polipropileno de baixa densidade e que seu frasco é de material facilmente reciclável (tereftalato de polietileno - 
PET ou PETE), já as outras duas marcas apresentam as mesmas informações e acrescenta que após a utilização deve-se levar o frasco com tampa aos pontos de coleta da cidade.

$\mathrm{O}$ item manteiga, em suas três marcas pesquisadas, relatam as simbologias, onde apresenta nas embalagens o polipropileno aceito para a reciclagem, apesar de ser mais duro e mais resistente ao calor que outros plásticos.

Em se tratando da carne foram observadas cinco marcas, porém nenhuma apresenta ações verdes, na sua embalagem ou em outro tipo material publicitário.

E para concluir a lista da cesta básica, os itens batata, tomate e banana também não apresentam sua origem, nem a forma de cultivo e não foi obtido informações nos caixotes de transporte.

\subsection{Rede supermercadista " $B$ "}

Para o supermercado "B", também foram verificados os treze produtos que compõem a cesta básica brasileira, foram analisados produtos de marcas diferentes as pesquisadas no supermercado "A".

No item leite, as mesmas características foram encontradas nos produtos pesquisados no supermercado "A", porém em uma das marcas evidencia os lembretes para reciclar a embalagem após seu descarte.

No caso do item feijão, o que difere das ações identificadas no outro supermercado pesquisado, foi apenas a simbologia que significa que o plástico das embalagens sendo reciclado poupa energia e recursos naturais.

Em se tratando do item arroz, foram identificadas as mesmas ações do supermercado A. Partindo para o item farinha, as simbologias demonstram praticamente os mesmos pedidos, reforçando para preservar a cidade limpa e reciclar as embalagens.

Já no item pão, acrescenta as seguintes frases, que reciclar é ter atitude e além de que se o plástico for reciclado valoriza os recursos naturais.

Partindo para os itens café em pó, açúcar e óleo, foi observada nas embalagens que o plástico utilizado na confecção das mesmas sendo reciclado economiza energia e recursos naturais, e fazendo isto se tem atitude.

E para concluir a parte dos itens da cesta que possuem ações verdes, vem o item manteiga que mostra as mesmas informações sobre o polipropileno aceito para reciclagem.

Nos itens batata, tomate, carne e banana, da mesma forma que na rede supermercadista “A”, não foi possível se observar ações de marketing verde. 


\subsection{Ações de marketing verde}

As principais ações foram identificadas em frases, símbolos ou selos nas embalagens dos produtos pesquisados. Para entender os significados desses, foram consultados os sites do Instituto Nacional de Metrologia e Qualidade e Tecnologia - INMETRO e do Instituto Brasileiro de Defesa da Natureza - IBDN, os principais encontrados nos supermercado "A" e "B" foram:

Fonte: Forest Stewardship Council (2012)

O selo FSC - Forest Stewardship Council (Conselho de Manejo Florestal) refere-se ao papel produzido através de fontes responsáveis, provenientes de florestas manejadas e de forma responsável.

Figura 2 - Símbolo 1: PETE

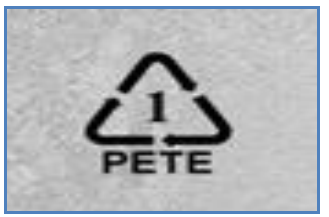

Fonte: INMETRO (2012)

A simbologia PET ou PETE (tereftalato de polietileno) - Provavelmente o rótulo de plástico mais comumente observado, encontrado em embalagens de refrigerantes e garrafas de água. O material pode ser facilmente reciclado em forro polar (I) e em fibras do tapete.

Figura 3 - Símbolo 4: LDPE

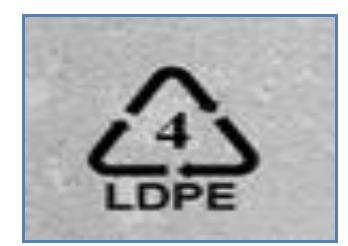

Fonte: INMETRO (2012)

Este é PEBD (polietileno de baixa densidade) - Este é o segundo mais comum dos rótulos plásticos, e é encontrado em sacolas plásticas e embalagens de comida congelada. Se 
aceito, ele pode ser reciclado em produtos como embalagens padronizadas de acondicionamento de lixo.

Figura 4 - Símbolo 5: PP

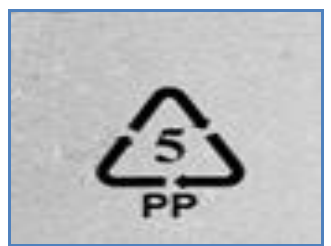

Fonte: INMETRO (2012)

Este PP é (polipropileno) - Esse plástico não é amplamente aceito para a reciclagem, e é usado para tampas de garrafas, canudinhos, embalagens para alimentos e frascos de medicamentos. Por ser mais duro e mais resistente ao calor que outros plásticos, quando é aceito para reciclagem pode ser aplicado em escovas, vassouras ou raspadores de gelo. $\mathrm{O}$ uso desse tipo de material, (apesar de ser maior a dificuldade para reciclar) e sua divulgação nos produtos são considerados ações de marketing verde.

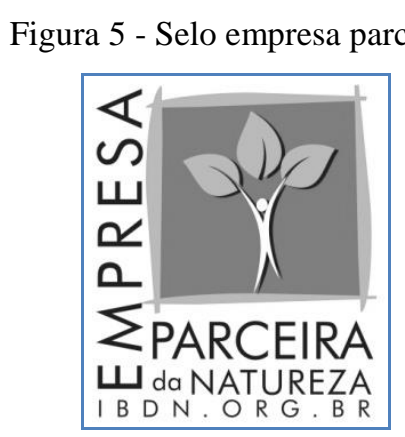

Fonte: IBDN (2012)

O Selo Empresa Parceira da Natureza é um programa de gestão sócio ambiental e tem como principais objetivos fomentar a consciência do valor dos recursos naturais, engajar a empresa e seus funcionários às ações que minimizem seus impactos ao meio ambiente, gerar crescimento de forma responsável visando à qualidade dos seus produtos e serviços focados no desenvolvimento sustentável (IBDN, 2012).

Além das ações de marketing verde foram identificadas ações de marketing social que merecem ser destacadas. foram consultados os sites do Instituto Materno Infantil de Pernambuco - IMIP e Associação Brasileira dos Fabricantes de Brinquedos - Abrinq.

Figura 6 - Selo empresa solidária 


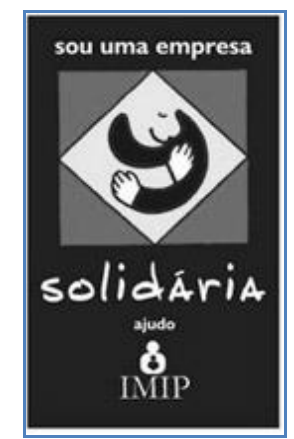

Fonte: IMIP (2012)

O Selo Empresa Solidária identifica as empresas que apoiam o IMIP, agregando valor aos produtos e serviços ao gerar um diferencial positivo frente aos seus consumidores e à concorrência. Trata-se de uma oportunidade para as empresa serem reconhecida não só pelos clientes, como também pelos seus funcionários, fornecedores e pela sociedade como um todo (IMIP, 2012).

Figura 7 - Selo empresa amiga da criança

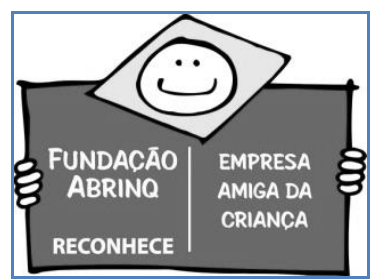

Fonte: Abrinq (2012)

O selo Empresa Amiga da Criança engaja o empresariado na defesa dos direitos da criança e do adolescente, mobilizando e reconhecendo empresas que realizam ações sociais para a promoção e defesa dos direitos das crianças e adolescentes (ABRINQ, 2012).

\section{Considerações finais}

O presente trabalho teve como objetivo identificar as ações de marketing verde encontradas nos produtos que compõem a cesta básica, em duas redes supermercadistas localizadas em Caruaru-PE.

Para atingir o objetivo geral, foram pesquisados os itens que compõem a cesta básica, através da pesquisa de campo foi possível identificar que nove produtos continham ações de marketing verde, em frases, selo e simbologias, esses foram: feijão, arroz, farinha, pão francês ou de forma, café em pó, açúcar, óleo ou banha e manteiga. Além dessas ações foram identificadas duas ações de marketing social que foram destacadas como importantes.

Diante do explicitado, é possível inferir que, as empresas utilizam algumas ações de marketing verde em produtos que compõem a cesta básica brasileira. Essas ações são 
consideradas importantes, mas ainda são insignificantes pelo impacto causado na natureza e sociedade.

A principal limitação encontrada no estudo esta relacionada a não disponibilidade das embalagens dos produtos como carne, banana, tomate e tomate, já que esses itens normalmente não são vendidos nas embalagens originais.

Para trabalho futuros é recomendado ampliação desse estudo para uma gama maior produtos, como também observar a influencia do marketing verde na decisão de compra dos consumidores.

Deve-se destacar que os conceitos apresentados são de relevante importância para se entender as relações do marketing verde e a satisfação dos clientes. No entanto, as teorizações e evidências apresentadas não têm a pretensão de ser tornar uma teoria definitiva e sim visam estimular o debate e a crítica junto à comunidade acadêmica.

\begin{abstract}
Concern for the environment has increased in recent decades, this fact is due to several factors, such as the necessity of man's survival and their perception of limited natural resources. Given the change of scenery, one of the tools that can be used by the company to allow reconcile profitability and social responsibility has to be called eco or green marketing, where it takes about a product and producer, as well as contributing to the adequacy of the companies with agencies responsible for environmental legislation, and against competitors by serving as a competitive variable. Thus the study sought to identify which actions are found in green marketing products that make up the basket, two supermarket chains located in Caruaru-PE. Through field research was able to identify eight products containing green marketing these actions were: Beans, Rice, Flour, Bread or French Fashion, Coffee Powder, Sugar, oil or lard and butter. Given the explicit, it can be inferred that with the implementation of the study it can be seen that companies are concerned about green marketing activities and begin to use in staples such as those that comprise the Brazilian basic basket.
\end{abstract}

Key-words: green marketing; basket; green products.

\title{
Referências
}

ABRINQ. Associação Brasileira dos Fabricantes de Brinquedos. Disponível em: <http://www.fundabrinq.org.br/>. Acesso em: 20 out. 2012.

BAROTO, A. Marketing verde. Paraná, 2007. Disponível em:

<http://www.faccrei.edu.br/gc/anexos/rvartigos_19.pdf>. Acesso em: 20 out. 2012.

CHURCHILL, G. A. \& PETER, P. (2000). Marketing: criando valor para o cliente. São Paulo: Saraiva.

DIAS, R. Marketing Ambiental. Gestão ambiental, responsabilidade social e sustentabilidade. São Paulo: Atlas, 1. ed., 2007.

DIAS, R. Marketing Ambiental Ética, Responsabilidade Social e Competitividade nos Negócios. São Paulo: Atlas, 2009.

DIEESE. Departamento Intersindical de Estatística e Estudos Socioeconômicos. Disponível em: <http://www.dieese.org.br/>. Acesso em: 20 out. 2012. 
JOHR, Hans. O verde é negócio. 2. ed. São Paulo: Saraiva, 1994.

IBDN - Instituto Brasileiro de Defesa da Natureza. Disponível em: 〈http://www.ibdn.org.br/novo/ >. Acesso em: 20 out. 2012.

INMETRO. Instituto Nacional de Metrologia e Qualidade e Tecnologia. Disponível em:

<http://www.inmetro.gov.br/>. Acesso em: 20 out. 2012.

IMIP. Instituto Materno Infantil de Pernambuco. Disponível em: http://www.imip.org.br/>. Acesso em: 20 out. 2012.

KOTLER P. Administração de Marketing. Análise, planejamento, implementação e controle. São Paulo: Atlas, Ed. 5, 1998.

LAS CASAS, A. L. Administração de marketing: conceitos, planejamento e aplicações à realidade brasileira. São Paulo: Atlas, 2006.

OTTMAN, J. A. Marketing verde. São Paulo. Ed Makron Books, 1994.

OTTMAN, J. A. As novas Regras do Marketing verde: Estratégias, Ferramentas e Inspiração para o Branding Sustentável. São Paulo: M. Books, 2012.

PEATTIE, K. Green Marketing. London: Pitman Publishing, 1995.

TEIXEIRA, A. O marketing verde. São Paulo, 2009. Disponível em: <http://construcao-

sustentavel.blogspot.com/2009/05/marketing-verde-por alessandrateixeira.html>. Acesso em: 08 nov. 2012.

\section{Dados dos autores:}

Nome completo: Jessiany Fernandes Braga

Filiação institucional: Faculdade Vale do Ipojuca FAVIP/DEVRY

Departamento: Administração

Função ou cargo ocupado: Graduada

Endereço completo: Rua Cônego Júlio Cabral, nº 178-A, Agrestina-PE.

Telefones para contato: (81) 9983-3582

e-mail: jhessyanny_kiss@hotmail.com

Nome completo: José Aparecido da silva

Filiação institucional: Faculdade Vale do Ipojuca FAVIP/DEVRY

Departamento: Administração

Função ou cargo ocupado: Graduado

Endereço completo: Rua Cônego Júlio Cabral, nº 178-A, Agrestina - PE.

Telefones para contato: (81) 9983-3582

e-mail: cidos_caramelos@hotmail.com

Nome completo: Lucyanno Moreira Cardoso de Holanda 
Filiação institucional: Faculdade Vale do Ipojuca FAVIP/DEVRY

Departamento: Administração

Função ou cargo ocupado: Professor Mestre

Endereço completo: Rua Manoel Alves de Oliveira, Catolé, Campina Grande - PB.

Telefones para contato: (83) 9654-2316

e-mail: 1holanda@favip.edu.br

Enviado em: 17/12/2012

Aprovado em: 01/04/2013 